\title{
ПОЛОСКОВЫЕ ФИЛЬТРЫ ЗАДЕРЖКИ
}

ЗАХАРОВ А. В., ИЛЬЧЕНКО М. Е., ТРУБАРОВ И. В., ПИНЧУК Л. С.

\author{
Национальный технический университет Украины \\ «Киевский политехнический институт», \\ Украина, Киев, 03056, пр-т Победы 37
}

\begin{abstract}
Аннотация. Рассмотрены новые конструкции миниатюрных полосковых фильтров задержки, которые реализованы на керамических материалах с высокой диэлектрической проницаемостью. Время задержки в новых неминимально-фазовых фильтрах составляет 7-12 нс на частотах около 1900 МГц с относительной шириной полосы частот 3,6-3,85\%. Размеры фильтров соизмеримы с размерами микроволновых керамических фильтров, используемых в портативных устройствах связи. Размеры исследованного в работе трехрезонаторного фильтра задержки на частоте 1900 МГц составили 8,4×5×2 мм при диэлектрической проницаемости материала $\varepsilon_{r}=92$, а 5-резонаторного фильтра - 9,2×8,6×2 мм. Фильтры отличаются от традиционных фильтров задержки. Два из рассмотренных фильтров содержат нечетное число резонаторов, а третий имеет четыре резонатора и обладает двумя перекрестными связями. Основу фильтров составляют пары близко расположенных друг к другу ступенчато-импедансных полосковых резонаторов, электромагнитная связь между которыми носит емкостной характер. Приведены результаты моделирования частотных характеристик различных фильтров задержки
\end{abstract}

Ключевые слова: фильтр задержки; время групповой задержки; коэффициент связи; частотная характеристика; полоса пропускания; перекрестная связь

\section{ВВЕДЕНИЕ}

Полосно-пропускающие фильтры с постоянным временем групповой задержки (фильтры задержки) широко используются в современных радиотехнических устройствах [1]. Развитие систем мобильной связи, особенно сотовой телефонии, вызвало значительный прогресс в направлении миниатюризации различных микроволновых полосно-пропускающих фильтров. Однако в фильтрах задержки результаты этой миниатюризации менее выражены, чем в фильтрах других типов. Например компания K\&L Microwave, Inc (CША) выпускает фильтр задержки TMD-2140-80/TD с центральной частотой 2140 МГц, размеры которого $51 \times 23 \times 7,4$ мм [2].

DOI: $10.20535 / S 002134701604004 X$

() Захаров А. В., Ильченко М. Е., Трубаров И. В., Пинчук Л. С., 2016
В настоящее время минимальные размеры на уровнях мощности выше 250 мВт имеют микроволновые керамические фильтры (microwave ceramics filters) [3, 4]. Они имеют ряд резонансных отверстий и изготавливаются в моноблочном исполнении из керамики с высокой диэлектрической проницаемостью $\varepsilon_{r}=$ 80-100. Размеры трехрезонаторного фильтра на указанную выше частоту составляют не более $5 \times 5 \times 2$ мм. Ввиду малых габаритов и высокой температурной стабильности частоты микроволновые керамические фильтры находят широкое применение. Однако они функционально ограничены и не обеспечивают постоянное время задержки.

Представляется перспективным создание фильтров задержки на основе симметричных 